\title{
Ortega y Gasset: universidade e ciência
}

\author{
Ortega y Gasset: University and science
}

http://dx.doi.org/10.5007/2178-4582.2015v49n2p4

\author{
José Mauricio de Carvalho e Mauro Sérgio de Carvalho Tomaz \\ Universidade Federal de São João Del Rei, São João Del Rei, MG, Brasil
}

\begin{abstract}
Neste artigo investiga-se como o filósofo espanhol Ortega y Gasset associa os limites da razão científica com a crise de cultura que ele enxerga na Europa. Indica-se que este será o tema da célebre conferência de Husserl intitulada A crise da humanidade europeia e a Filosofia. Porém, fica esclarecido que a análise de Ortega é mais ampla que a realizada por Husserl. Ortega avalia que a vida inautêntica é o outro aspecto da crise de cultura que decorre, além do entendimento inadequado da ciência, do comportamento infantil e gozo irresponsável do homem massa. Logo, a análise orteguiana tem pontos comuns com a feita por Husserl, mas é mais ampla por incluir um elemento ontológico, ligado à condição do homem, à raiz da crise de cultura que então se experimentava.
\end{abstract}

Palavras-chave: Universidade; Conhecimento; Ciência; Ortega y Gasset.
This article investigates how the Spanish philosopher Ortega y Gasset associates the limits of the scientific reason with the culture crisis that he sees in Europe. This theme is indicated to be the theme of Husserl's famous talk called The European Humanity Crisis and the Philosophy. However, Ortega's analysis is wider than the one made by Husserl. Ortega evaluates that the unauthentic life is another aspect of the culture crisis that happens in addition to the inadequate understanding of the science, of the childish behavior and the irresponsible enjoyment of mass-man. So, the orteguian analysis has common points with the made Husserl, but it is broader because it includes an ontological element linked to the human condition, as a result of the crisis of the culture that was then being experienced.

\section{Considerações iniciais}

A preocupação de Ortega y Gasset com o papel da universidade no enfrentamento da crise de seu tempo não é inédita na tradição ocidental. Ela recorda o projeto de Johann Fichte que associou a reconstrução da nação alemã, depois da invasão napoleônica no início do século XIX, à reorganização da sua universidade. Desde o texto de Fichte, Por uma universidade orgânica, a universidade germânica tornou-se centro de pesquisa científica, organização essencial para o desenvolvimento cultural do país e modelo para as instituições universitárias do ocidente.

Mais de um século depois, em 1930, Ortega escreveu dois livros importantes: La rebelión de las masas e Misión de la universidad. O início daquela década significou, em sua trajetória intelectual, uma alteração de rumo da 
meditação filosófica, conforme observou Jaime de Salas na apresentação de La última filosofia de Ortega y Gasset. Os dois livros de Ortega representam a abertura de nova fase, que mesmo sem romper com as teses iniciais do raciovitalismo, centra a investigação na cultura ocidental, pela inserção da vida na história e construção da chamada razão histórica. La rebelión de las masas e Misión de la universidad propiciam compreensão mais clara da intenção de Ortega, na trilha apontada por Fichte, de enfrentar a crise de seu tempo com a reforma da Universidade.

Em La rebelión de las masas o filósofo concluiu que o fenômeno marcante de seu tempo, a inautenticidade da vida, não era exclusivamente espanhol, como acreditara uma década antes em España Invertebrada (1921), mas uma crise ampla, europeia e ocidental. Em España Invertebrada escrevera: "Quando numa nação a massa se nega a ser massa - isto é, a seguir a minoria diretora -, a nação se desfaz, a sociedade se desmembra, e sobrevêm o caos social, a invertebração histórica" (ORTEGA Y GASSET, 1994a, p. 93).

Do que trata mesmo La rebelión de las masas? Do mesmo tema de España Invertebrada, porém ampliado o problema da crise de cultura para a Europa e todo o ocidente, como se lê em Ortega y Gasset: crise da Espanha e problemas políticos: "A obra (...) trata a crise da Europa e dos sistemas totalitários surgidos naquele tempo. O livro investiga ainda a raiz moral da crise e dos problemas políticos que emergiam naquele momento histórico" (CARVALHO; BESSA, 2012b, p. 120). O tema das massas era essencial naqueles dias, investigar e esclarecer o propósito da massa que pretendia dirigir a cena pública através de sistemas fechados e de um estilo próprio de vida.

E como seus comentaristas interpretam as duas obras de 30? A maneira usual é associar a preocupação pedagógica de Ortega y Gasset e o eixo nuclear de sua Filosofia. E qual é este eixo? O fato de a vida de cada homem ser única e seu sentido constituir-se na realização do núcleo íntimo nela presente, projeto que ele denomina autenticidade. Procuram, então, seus comentaristas demonstrar que o programa educacional exposto em Misión de la Universidad não contradiz as exigências de vida autêntica, tema central da ontologia orteguiana, construída desde as primeiras obras. Pode-se dizer que seja mesmo o contrário, a Universidade deve promover a vida autêntica. Foi essa, por exemplo, a linha de reflexão de Margarida Amoedo em seu extenso livro José Ortega y Gasset: a aventura filosófica da educação (2002).

Amoedo mostrou que vencer a crise de civilização da primeira metade do último século exigia a superação do tipo de homem que então existia e só se podia fazê-lo com uma mudança cultural originada na reforma educacional. Ortega y Gasset propõe superar a crise de cultura com um programa educa- 
cional, mas é preciso entender quem era o homem que perdeu o compromisso com a autenticidade. Em outras palavras, que homem era aquele que precisava de um novo tipo de educação para vencer o desafio da autenticidade? Era o homem-massa. E quem era o homem-massa? Alguém que não tinha compromisso com o núcleo mais íntimo de si mesmo, alguém que não se ocupava em ser melhor, isto é, alguém que ignorava suas exigências íntimas e as necessidades de seu tempo, e era, por isto, uma espécie de novo bárbaro. Em síntese feita em Ética e no discurso político de Ortega y Gasset encontra-se rápida caracterização desse novo bárbaro como se segue: "O novo bárbaro que emergia no horizonte histórico possuía características que o diferenciavam do antigo: senhorio satisfeito, jovem mimado e bárbaro especialista" (CARVALHO; BESSA, 2012c, p. 102).

E para entender quem foi o homem-massa não se pode perder de vista como Ortega compreendeu a vida. Ele a pensou como um que fazer, como um faciendum, processo que nascia da execução de um projeto vital. A elaboração do projeto vital não é exclusivamente racional, mas inclui uma orientação íntima para que o resultado esteja na linha da autenticidade. Essa atitude se alcançava por meio de uma jornada interior (ensimesmamento) e com formação adequada, daí a importância do tipo de formação universitária oferecida pela sociedade.

Quando Misión de la universidad é aproximado da crise de cultura identificada em La rebelión de las masas, compreende-se a preocupação do autor em submeter a produção e transmissão do conhecimento aos desafios da vida autêntica. Como tema de investigação, atende ainda um problema da geração orteguiana: explicar como a Universidade contribui para a formação do homem e do seu papel nas sociedades contemporâneas. Uma ideia da questão pode ser obtida com a leitura da sessão que a revista Estúdios Orteguianos (2001) lhe dedicou. Dos onze artigos ali existentes destaque-se três com tal propósito: La misión de la Universidad al servicio de la necessidad pública, de Margarita Padorno; Mission de la Universidad en el homenaje de 18 de noviembro de 1955, de Rafael Romero; El papel de la Universidad contra la barbárie, de Margarida Amoedo. Esses artigos fornecem uma chave hermenêutica para a compreensão do texto orteguiano, aproximando a noção de crise cultural com a resposta que a Universidade pode dar a ela.

Este artigo não pretende seguir na direção desses estudos que é uma linha de investigação bem conhecida, mas aprofundar os motivos pelos quais o conhecimento científico insuficiente, que é um dos aspectos da crise da cultura, conforme reconhece Ortega, tem contribuído significativamente para o surgimento do homem-massa. Trata-se, mais especificamente, de investigar o modo orteguiano de entender os motivos pelos quais a ciência 
praticada na Universidade era um dos provocadores da crise de cultura do momento.

Para que fique claro que não se tratava de preocupação isolada de Ortega, mas de um desafio mais amplo, lembramos que entre os anos de 1934 e 1937, Husserl examinará o problema e pronunciará a célebre conferência $A$ crise da humanidade europeia e a Filosofia onde aproximou a crise da cultura da interpretação unilateral da ciência:

Trata-se de problemas de procedente ingenuidade, em virtude da qual a ciência objetivista toma o que ela chama o mundo objetivo como sendo o universo de todo o existente, sem considerar que a subjetividade criadora da ciência não pode ter lugar legítimo em nenhuma ciência objetiva (HUSSERL, 1996, p. 80).

Antes de examinar essa questão vamos aprofundar a noção orteguiana de homem-massa, pois ele é o personagem da crise na avaliação de Ortega y Gasset.

\title{
O homem-massa: esboço de caracterização
}

O homem-massa é identificado por Ortega y Gasset por três características marcantes: satisfação senhorial, comportamento de um jovem mimado e especialização bárbara. E qual a relação entre o homem-massa e a crise vivida daqueles dias? Ortega explica que o homem-massa aspirou ser o centro do processo cultural e dar o tom da vida cultural, como foi explicado em $O$ século XX em El Espectador de Ortega y Gasset: a crise como desvio moral:

\begin{abstract}
A característica fundamental da crise do século XX era uma atitude comum que, segundo Ortega y Gasset, marcava a massa e a minoria da sociedade. (...). O que ele observa é que no século XX, as minorias mais bem educadas nos diversos campos culturais não assumiam a tarefa de dirigir a sociedade, não respondiam aos novos desafios que a vida apresenta, por sua vez a formação universitária cultivava um saber muito especializado e ignorava quase todos os assuntos (CARVALHO, 2010, p. 15).
\end{abstract}

Primeiro esclareçamos: o que é a satisfação senhorial? No capítulo XI de La rebelión de las masas, Ortega diz que o homem-massa está satisfeito com o que é, absolutiza seu modo de vida, supõe que ela está pronta e é fácil, não enxerga seus riscos. Não entende que precisa ser melhor do que é para vencer os novos desafios que a vida traz. Ele não se preocupa com as limitações da 
existência e acredita que seus problemas serão resolvidos com o conhecimento herdado das gerações passadas, sem precisar fazer nada novo. Assim, acreditando dispor de tudo o que necessita para viver, deseja apenas gozar a vida que já está pronta. Ortega se refere a esta satisfação do seguinte modo:

\begin{abstract}
Este contentamento consigo leva-o a fechar-se a toda instância exterior, a não escutar, a não colocar em questão suas opiniões e a não contar com os demais. Sua sensação íntima de domínio o incita constantemente a exercer predomínio (ORTEGA Y GASSET, 1994b, p. 207).
\end{abstract}

E qual o resultado dessa satisfação? O que o filósofo aponta como a segunda característica do homem-massa, a de agir como menino mimado. Diz Ortega que uma criança mimada é uma espécie de bárbaro: "Esse repertório de fazeres (contentamento íntimo e falta de compromisso) nos faz pensar em modos deficientes de ser homem, como um menino mimado, e primitivo rebelde, quer dizer, como bárbaro" (Ibid., p. 207).

Na avaliação de Ortega y Gasset, portanto, pertencer à massa não exige esforço, de modo que a vida rotineira e medíocre do homem massa revela um vazio moral. O homem-massa está satisfeito com o que é e não se esforça para ser melhor, não cuida de sua vocação.

E como se comporta um menino mimado? Ele não aceita ser contrariado e fica furioso quando isto ocorre. Ele deseja ter tudo sem se esforçar. Uma sociedade de homens-massa é uma coletividade infantil que deseja gozar sem limites e viver sem esforço. Também pode ser dito que se trata de uma sociedade de direitos sem obrigações correspondentes.

O homem-massa fica encantado com os resultados da tecnologia, está deslumbrado e feliz com os instrumentos que dispõe para viver, porém não avalia quanto esforço, riscos e angústias foram necessários para produzir o aparato tecnológico hoje disponível. Ele é um perigo para as futuras gerações, porque não se empenha em fazer nada novo, nada melhor. Tal circunstância leva Ortega y Gasset a considerar que, quando o homem-massa se torna o principal protagonista da vida cultural, a decadência é iminente: "é preciso dar o alerta e anunciar que a vida se encontra ameaçada de degeneração" (Ibid., p. 210).

A terceira característica do homem-massa é o de ser um especialista, um profissional formado para praticar a ciência moderna, mas incapaz de refletir criticamente os meandros do conhecimento e os limites da ciência. Essa formação insuficiente também ajuda a formar o homem-massa, quer dizer, faz dele criatura primitiva, um bárbaro. E por que ele é bárbaro se conhece bem uma profissão? Por que é tratado como primitivo se passou pelos bancos 
universitários e é um doutor? Porque domina um campo do saber, mas ignora seus limites sem desconfiar do que está além dele. Dito de outro modo no capítulo Totalitarismo e ética em Ortega do livro Poder e moralidade : "Ele é o ignorante especialista. Aprendeu uma técnica sofisticada ou uma profissão exigente, mas é ignorante de quase todos os outros assuntos" (CARVALHO; BESSA, 2012a, p. 121). Assim, o conhecimento limitado da ciência moderna, tomado como verdade suficiente e saber completo, alimenta a crise de cultura de que estamos tratando.

O fato de ser pouco culto, mas diplomado em uma ciência, torna-o prepotente. Ele se torna igualmente autoritário, opressivo, tirânico, acreditando que o diploma faz dele um sábio. E a prepotência torna-o um insubordinado que não reconhece nenhum talento ou conhecimento maior que o seu. Ele pensa ser um sábio de uma sociedade de sábios. Por isso não consegue viver uma vida autêntica.

A vida autêntica só poderá ser recuperada por uma nova geração de estudantes que, entre outras coisas, entenda os limites da ciência e aprofunde o sentido da verdade da ciência. E por que o homem daqueles dias se tornou um ignorante diplomado? O que houve com a ciência? Por que seus cultores se tornaram bárbaros? Eis a questão central deste artigo.

\section{O homem-massa e a universidade}

Como dito no item acima, em La rebelión de las masas Ortega caracterizou o homem-massa como: senhorio satisfeito, menino mimado e bárbaro especialista. Portanto, uma de suas características é a acentuada especialização da sua educação, fato decorrente da especialização promovida pelas ciências modernas. E por que a especialização ajudou a produzir o homem-massa? Mostramos que, para Ortega y Gasset, se uma ciência não se separa das demais, "o trabalho nela sim tem que ser - irremediavelmente - especializado" (ORTEGA Y GASSET, 1994b, p. 217). O tipo de especialização vinda do ensino da moderna ciência faz surgir na História um homem que conhece muito sobre mínimas regiões do universo, mas nada do restante. Essa circunstância, o ser só um especialista, evidencia mais sua ignorância que seu conhecimento. Portanto, não se trata de recusar o conhecimento da ciência e a especialização que ela exige, mas o tipo de especialização que surgiu com a formação universitária insuficiente.

A crítica embutida na análise orteguiana é importante porque a organização universitária é imprescindível no mundo atual, ao mesmo tempo em que cresce a importância da ciência para governos e sociedades. Além disso, o destino do homem ocidental encontra-se atrelado ao conhecimento racional. E qual o 
significado da crise de cultura? É que o modo de pensar a ciência elaborado na modernidade forjou uma interpretação inadequada da realidade e do processo cultural, e era esse o problema, como resume Juan Álvares em Crisis de crencias y revoluciones científicas: "[Essa mentalidade] privilegiou a razão científica natural e a técnica anexa a ela como forma de interpretar o mundo e transformar a circunstância, de constituir o mundo" (ÁLVARES, 2003, p. 116).

Ortega diria, mais especificamente, que fazer ciência é essencial para o futuro do homem ocidental, mas é preciso pensar a realidade de outro modo que não apenas pelas categorias da ciência. Tratar o ensino da ciência é assunto que afeta a organização das universidades, concebidas segundo este modelo ocidental, e também o futuro do homem ocidental, conforme escreveu Husserl em A crise da humanidade europeia e a Filosofia próximo da compreensão orteguiana:

A crise da existência europeia só tem duas saídas: ou o ocaso da Europa num distanciamento de seu próprio sentido racional da vida, o afundamento na hostilidade ao espírito e na barbárie, ou o renascimento da Europa a partir do espírito da Filosofia, mediante um heroísmo da razão que triunfe definitivamente sobre o naturalismo (HUSSERL, 1996, p. 85).

Estas observações de Husserl são concordes, no essencial, com o que dizia Ortega, menos a explícita confiança do espanhol em que a crise identificada por ambos não significava um risco para a Europa, mas, dissera-o em Investigações de Psicologia: "o anúncio de uma incalculável ampliação e renovação do pensar humano" (ORTEGA Y GASSET, 1997, p. 343). Portanto, Ortega era mais otimista que Husserl no poder que as crises tinham na renovação da vida.

Diante do que foi dito acima deve-se perguntar: o que pretendia a universidade europeia naqueles dias? Ortega avalia que ela era uma instituição organizada para realizar dois objetivos: formar profissionais e preparar pesquisadores. Estes últimos em número menor, a maioria estudava mesmo para ser: "médico, farmacêutico, advogado, juiz, economista, administrador público, professor de ciências e de letras (...), etc." (ORTEGA Y GASSET, 1997, p. 319) que são profissionais que a sociedade necessita em maior número.

O que é fundamental para superar o tempo das massas é que o profissional e o pesquisador tornem-se cultos. E o que é ser culto? É ser mais que um especialista em alguma ciência, é possuir ideias claras sobre o funcionamento do universo e crenças justificáveis sobre ele. É isso o que fará do universitário um homem culto e apontará para ele o caminho da autenticidade. Segundo Ortega y Gasset "cultura é o que salva do naufrágio vital, o que permite ao homem viver sem que sua vida seja tragédia sem sentido ou radical aviltamen- 
to" (Ibid., p. 321). E ser culto exige mais que conhecer uma ciência, embora o conhecimento das principais referências científicas seja parte do que deve conhecer o homem culto. Ser culto pede uma síntese da ciência do seu tempo.

E por que é assim? José Carlos Rothen, em A universidade e sua missão segundo Ortega y Gasset, resume a visão orteguiana do assunto da forma seguinte: "é na cultura que o homem encontra os valores vitais de sua existência, o repertório de convicções que norteia sua ação" (ROTHEN 2011, p. 69). A cultura está associada à vida autêntica, acrescenta Ortega y Gasset na obra que estamos examinando, pois ela é resposta aos problemas históricos, já que "é forçoso viver à altura dos tempos" (ORTEGA Y GASSET, 1997, p. 312). A cultura e a vida autêntica pedem que se saiba ciência cujo peso é cada vez maior na cultura.

A crise de cultura que nasce com o homem-massa; surge porque o homem médio não foi preparado para responder aos desafios de seu tempo, dando origem "a uma época de terrível incultura" (ORTEGA Y GASSET, 1997, p. 344). Para combatê-la é preciso distinguir formação cultural de preparo profissional, sendo que ambos dependem da ciência "que está inseparavelmente ligada ao destino do homem europeu” (Ibid.,, p. 350).

A conclusão de Ortega é que "a universidade é distinta, porém inseparável da ciência" (Ibid., p. 351). Quando perde o propósito de formar o homem culto, a universidade deixa de ser essencialmente o que ela é e se torna inautêntica como o próprio homem-massa. É o que ocorre ao homem ou instituição quando afastada de seu núcleo vital: torna-se uma coisa falsa. Cabe então perguntar: por que ela se tornou uma instituição inautêntica? Ela não foi, na Idade Média, um templo do saber, uma instituição que ensinava ciência e formava o melhor homem para aqueles dias? O que mudou? A nova forma de fazer ciência? Será a ciência nova promotora da incultura? O que houve com a ciência?

\section{O homem-massa e a nova ciência}

Em 1930 e nos anos seguintes, Ortega y Gasset escreveu artigos sobre a ciência que reportam aos dois livros citados e esclarecem como o conhecimento limitado da ciência contribui para a crise de cultura do tempo das massas. Neles, examinará o tipo de conhecimento científico do profissional formado pela universidade de então. Este conhecimento limitado explica a falta de cultura do homem-massa, embora diplomado por uma universidade, ele desconhece os limites e o significado cultural da ciência. No artigo Vicisitudes en las ciencias, como se comenta em Introdução à filosofia da razão vital de Ortega y Gasset, Ortega indicou que "no século XVIII muitos filósofos apresentaram a ciência moderna como um saber prevalente, espécie de ideal 
da razão" (CARVALHO, 2002, p. 282). A citação indica o problema presente na raiz da crise de cultura e na formação do homem-massa: a mistificação da razão científica contribuiu para ocultar suas limitações. A idealização da razão científica promoveu uma supervalorização da ciência que influenciou toda a cultura. Tudo precisava ser científico para parecer confiável. Explica o filósofo esta pretensão da ciência de dominar os outros aspectos da cultura: "Durante o século XIX, todas as ciências exercitaram o mais desaforado imperialismo. Era este o modo vital que inspirou toda esta época em todos os aspectos" (ORTEGA Y GASSET, 1994d, p. 63).

No entanto, não é apenas a supervalorização da ciência o problema a ser enfrentado. A ciência revela limites no trato do seu objeto que devem ser meditados, lembrava Ortega em Las ciencias en rebeldia, mas tais limites são desconsiderados pelo homem de ciência: "Agora cada ciência não só aceita sua nativa falta, mas repele toda a pretensão de ser legislada por outra" (Id., 1994e, p. 105). Ortega lembra em Vicisitudes en las ciencias, que Galileu pensou a Física Moderna como ciência de medida exata. Ele acreditava que "a Física é Matemática, quer dizer, que os fenômenos naturais se comportam matematicamente" (Id., 1994d, p. 65). E esse é um dos limites e crenças da Física que ela incorporou. No entanto, avalia Ortega: "a realidade não se compõe de letras matemáticas - tal foi o erro de Galileu" (Ibid., p. 67). Urbano Zilles, na introdução que fez para $A$ crise da humanidade europeia e a Filosofia, comenta que Husserl pensava algo parecido na mesma época: "Mas, segundo Husserl, a objetivação da natureza, obtida por Galileu, não conduz ao ser das coisas (...). A natureza idealizada passou a substituir a natureza pré-científica. A matematização da natureza violentou o ser natural” (HUSSERL, 1996, p. 26).

Em Las ciencias en rebeldia o filósofo diz que Einstein recusa tal crença, rejeitando submeter a Física à Matemática. Explica-o nos seguintes termos:

\footnotetext{
Para mim, o ponto da maior genialidade de Einstein está na decisão com que se liberta do tradicional preconceito: quando observa que os fenômenos não se comportam segundo a lei de Euclides e se encontra em conflito com a geometria e a exclusão da física, não vacila em declarar esta soberana (ORTEGA Y GASSET, 1994e, p. 104).
}

Se Galileu tivesse em mãos instrumentos de medida rigorosos encontraria uma realidade não retratável pela Matemática que conhecia e a nova ciência somente se desenvolveria numa perspectiva diversa da que utilizou. Assim, a essência da vida não se deixa medir de forma exata como Galileu pensou ser possível; mundo é limitação. E, conclui o pensador em Vicisitudes en las ciencias: "este ser manco, é o que se chama destino, vida. O que nos 
falta e nos oprime é o que nos constitui e nos sustenta" (Id., 1994d, p. 68). Fica, pois, subentendido que quem não percebe que a essência do mundo não se mede não alcançou a capacidade crítica do homem culto. E é esta formação deficiente da ciência não criticada, e deficientemente assimilada pelos profissionais formados nas universidades, a ciência do homem massa.

Num outro artigo publicado no mesmo ano e intitulado O imperialismo da Física, Ortega lembra que o sucesso daquela ciência foi associado aos cômodos da vida que ela proporciona. "Em seu Discurso sobre o espírito positivo, o mesmo Comte havia já sugerido que a técnica regimenta a ciência e não o contrário" (ORTEGA Y GASSET, 1994j, p. 96-97). Esta forma de pensar, que submete a verdade científica à sua utilidade, é outro erro de compreensão da ciência praticada pelo homem-massa. Ela oculta o fato de que a verdade da ciência é teórica e não prática. E lembra, a título de exemplo, a atuação do médico, profissional extremamente valorizado e necessário à sociedade, "que emprega o resultado de várias ciências, mas que não é homem de ciência, alma teórica" (Ibid., p. 88). Nesse artigo rejeita, pois, a noção de que o conhecimento científico é válido pelas comodidades que permite, e lembra que a vida na China era muito cômoda, enquanto a ciência se desenvolvia, no mesmo momento, na Grécia Antiga sem proporcionar os meios cômodos de vida de que dispunham os chineses. É a pouca capacidade crítica e a falta de perspectiva histórica que leva a tomar como essencialmente verdadeiro o que só circunstancialmente o é, isto é, tomar como critério científico de verdade o bem-estar e as comodidades que a técnica oferece à sociedade.

Num outro artigo La ciencia es mero simbolismo (1994h), também de 1930, Ortega retoma a tese de que a verdade científica tem qualidades importantes, como dissera em Vicisitudes en las ciências, a exatidão e a certeza. E também reafirma o dito em $O$ imperialismo da Física de que esses critérios são magníficos quando se olha a Física desde dentro. Contudo, para conhecer profundamente a Física é preciso sair de dentro dela para ir ao subsolo onde ela se sustenta. Sobre este assunto somente formula uma explicação clara e completa do significado de crença na cultura muitos anos depois, em 1947, quando escreveu La idea de principio en Leibniz y la evolución de la teoria deductiva. No parágrafo 26 esclarece que "uma crença não é um ideoma, mas um draoma, uma ação vivente ou ingrediente invisível dela" (ORTEGA Y GASSET, 1994k, p. 259). Também afirma que toda Filosofia é um conjunto de ideias, mas que elas se sustentam sobre um substrato que não se mostra completamente na teoria; no entanto, é uma crença sobre a qual se sustenta o sistema de ideias veiculadas na cultura. E no que se refere à ciência? Qual a crença que a embala? Na ciência o que conta é o resultado, se eles existem não se necessita de prova intelectual. Escreve: "não sendo o método uma 
ciência, não há que prová-lo com razões, senão com resultados e sucesso" (Ibid., p. 257).

E, neste novo espaço da ciência moderna, pautado pelo resultado, nos deparamos com a falta de correspondência entre o conteúdo da Física e o mundo corpóreo. Explica em $O$ imperialismo da Física: "são como dois idiomas diferentes que permitem unicamente a tradução" (ORTEGA Y GASSET, 1994g, p. 101). A Física não tem mais que correspondência simbólica com o mundo, conclui e justifica citando Einstein para quem "não há caminho lógico que conduza aos princípios da teoria" (Ibid., p. 102). Isto significa que uma compreensão profunda da Física demanda uma compreensão teórica que vá além da exata correspondência entre a teoria Física e o seu resultado. Se não alcançar tal dimensão, o conhecimento da Física permanece superficial e não alcança seus elementos estruturantes.

No já mencionado Las ciencias em rebeldia, Ortega relata as dificuldades de compreensão de ciências que, no século XIX, aspiravam ser o que não eram. Aquele foi um tempo em que: "a Física quis ser Metafísica e a Filosofia quis ser Física e a poesia, pintura, a música e a política não se contentavam em ser-lo, senão que aspiram ser credo religioso e, o mais desaforadamente, a fazer felizes os homens" (Id., 1994e, p. 103). Essa dificuldade foi superada, mas não o entendimento de que verdade científica é a praticada "pela Física e disciplinas congêneres" (Ibid., p. 103). Esta crença somente foi enfrentada no século XX, quando cada ciência ocupou-se de seu objeto.

$E$, naqueles dias, evidenciou-se a dificuldade da Filosofia, pois enquanto todas as ciências focavam seu objeto de modo exato, a Filosofia deparouse com um objeto enorme, completo: "integral, o autêntico todo, o que não deixa nada fora e, por isto mesmo, é a única ciência que se basta" (Ibid., p. 107). Depois de observar as dificuldades que há em enfrentar um tão vasto objeto, Ortega aponta uma grande dificuldade de todas as teorias do conhecimento "a de não perceber a inicial incongruência que existe entre a necessidade que o homem tem de conhecer e as faculdades com que conta para isto" (Ibid., p. 109). Todas essas dificuldades exigem boa capacidade de análise e uma visão global do conhecimento que é própria do homem culto, e é este homem que a Universidade está desafiada a formar.

Além das dificuldades epistemológicas e dos problemas envolvendo a prática da ciência, a formação do homem culto depara-se com uma questão central: o compromisso que o fazer ciência representa na vida de quem vai à universidade. É que os criadores da ciência, ou de quem faz dela um compromisso de vida, tem com a ciência uma aproximação vital que o estudante comum normalmente não tem, explica Ortega em Sobre el estudiar y 
el estudiante. Este artigo de 1933 oferece novos elementos para se entender as dificuldades nascidas do conhecimento insuficiente da ciência. No caso, o ato de estudar não é propriamente compromisso de entrega como foi para os criadores da ciência e é para os integralmente dedicados a encontrar a verdade científica. Para estes últimos, uma franca minoria, "se não as houvessem encontrado haveria de considerar fracassadas suas vidas" (ORTEGA Y GASSET, 1994f, p. 546).

Para quem estuda ciência como obrigação social, ocupa-se de algo que não é propriamente seu, embora esta necessidade social seja cada dia maior, pois "se uma geração deixasse de estudar, nove décimos da humanidade morreria fulminantemente" (Ibid., p. 553). E assim, às dificuldades epistemológicas nascidas da prática científica, expressas nos artigos anteriores, os descaminhos da razão experimental na modernidade, soma-se este outro problema que toca o homem de seu tempo: "ele não tem necessidade íntima de estudar ciências que não têm, para ele, sentido imediato, autêntica necessidade" (Ibid., p. 548). O que o leva a aprender ciência é uma necessidade social da qual ele se serve para arrumar ocupação e retirar dela sustento.

$\mathrm{Na}$ terceira lição das Investigacões de Psicologia, Ortega não apenas deixa claro a especificidade da Psicologia diante das outras ciências da natureza, mas indica um aspecto fundamental para o ensino da ciência em geral. Ao forjar a independência das ciências, o homem moderno percebeu que podia investigar separadamente os problemas das diversas ciências, isto é, existem verdades científicas que podem ser ditas isoladamente. Contudo, se mantidas isoladamente não são verdades, razão pela qual o homem culto é aquele que tem, pelos menos em linhas gerais, uma visão atual do universo e dos grandes problemas nele identificados, além de desenvolver a capacidade crítica e filosófica que a reflexão sobre os fundamentos da ciência propicia. Eis o que diz Ortega sobre o que o homem culto deve saber: "Existe, pois uma interdependência essencial entre todas as teorias, entre todas as ciências. Nenhuma é verdade, verdadeiramente, senão dentro do quadro geral da ciência" (ORTEGA Y GASSET, 1997, p. 456-7).

Ortega observa que a crise presente na cultura ocorreu junto à revisão no significado da ciência. Afirma-o, em 1933, no livro En torno a Galileo: "É tão pouco autêntico como se sustentasse que a ciência é tudo, que só a ciência salva o homem, etc. Isto era autêntico em 1833, porém não em 1933" (Id., 1994i, p. 139).

A mudança de significado da ciência também foi captada numa série de artigos publicado em La Nación, em 1937, sob o título geral de Bronca en la Física (19941) Na avaliação de Ortega, a crise de cultura provocada pela 
supervalorização da ciência moderna identificada foi concomitante à revisão na compreensão da ciência, iniciada pelas mudanças na Física, considerada ciência exemplar. Essa mudança foi percebida no debate entre o Dr. Hebert Dingler e a fina flor da pesquisa Física representada pelos doutores: Milne, Eddington, Wittrow, Whekle e Robertson. Ele resumiu as mudanças de então no terceiro desses artigos denominado Conversión de la Física en Geometria : "a Física, nossa ciência exemplar, se encontra a ponto de mudar subitamente de aspecto e de caráter" (Id., 1994j, p. 279). Essa mudança representava dar um passo além da origem histórica daquela ciência, quando, segundo Galileu, os fatos foram submetidos à razão matemática. Diz o filósofo: "Galileu representa frente a Aristóteles a não crença em que a razão da natureza seja a mesma do homem" (Ibid., p. 280). A mudança na Física foi aperfeiçoada naqueles dias por meios mais precisos de observação. Ele diz:

A teoria da relatividade, auxiliada por meios de observação mais precisos mostrou que o corpo dos puros teoremas chamado geometria euclidiana, não se cumpre nos fenômenos da natureza, e que, em contrapartida, cumprem-nos o teorema da geometria de Riemann (ORTEGA Y GASSET, 1994i, p. 282).

Ortega concluiu, com essa revisão crítica sobre o papel da ciência, que o rigor da observação era uma exigência para superação da crise de cultura. Clareza sobre perspectivas e limites da ciência, condição para superar a barbárie do especialismo.

\section{Considerações finais}

Neste artigo indicou-se que Ortega y Gasset toma de Fichte a ideia de que a crise da cultura poderia ser enfrentada com a reforma da universidade. Explica-se o modo como Ortega expõe os limites da ciência e o significado do seu conhecimento insuficiente para a crise de cultura. Ortega acredita que o homem culto superará o conhecimento insuficiente da ciência.

Sobre o destino político da sociedade europeia, embora tenha sido vencido o risco das sociedades totalitárias, o homem no século XXI enfrenta uma espécie de continuação da crise do último século, vendo surgir um novo tipo de homem-massa' Uma crise em que o senhorio satisfeito tornou-se hedonista ansioso, mas sem conseguir superar as dificuldades vindas da especia-

No livro Ética indica-se a nova face do homem-massa que, sem superar a barbárie da especialização,tornou-se um "consumista compulsivo, sorvendo (ansiosamente) o que dá prazer imediato porque teme a falta de sustentação do crescimento econômico e a emergência de dificuldades econômicas que reduzam o enriquecimento global (e seu sonho irreal de prazer sem limite)" (CARVALHO, 2010, p. 163). 
lização da ciência e da redução da capacidade crítica da geração nascida em meio à especialização e aos computadores. Este comportamento inunda os espaços públicos e a vida social contemporânea.

Somente o homem culto, dizia Ortega, capaz de sistematizar as grandes linhas da ciência contemporânea, mas, sobretudo, capaz de criticar os limites da ciência, pode superar os problemas que a independência das ciências, no curso na modernidade, provocou. A revisão do papel e significado da ciência, o rigor da observação, é exigência para superação da crise. A clareza que daí surge sobre perspectivas e limites da ciência é condição para superar a barbárie do especialismo.

O homem culto não pode desconhecer o significado e limites da ciência, mas ao conhecê-los consegue entender que a ciência não é toda a cultura. Procura-se, ainda, indicar que a vida inautêntica é outro elemento da crise de cultura e ela se manifesta no comportamento infantil e no gozo irresponsável do senhorio satisfeito. Deste modo, a crise tinha um aspecto intelectual que foi detalhado acima, mas também um elemento ontológico ligado à condição do homem: a falta de compromisso com seu núcleo íntimo, a dificuldade de ensimesmar-se ou de meditar.

\section{Referências}

ÁLVARES, Juan Ramos. Crisis de creencias y revoluciones cientificas. Revista de Estudios Orteguianos. Madrid: Fundación Ortega y Gasset. , n. 6, p.101-118, 2003.

AMOEDO, Margarida I. Almeida. El papel de la Universidad contra la barbárie. Revista de Estudios Orteguianos. Madrid: Fundación Ortega y Gasset, n. 2, p. 111-118, mai. 2001.

. José Ortega y Gasset: a aventura filosófica da educação. Lisboa: Imprensa Nacional -

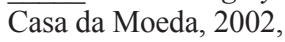

ARAÚJO, José Carlos de Souza (Org.). A universidade iluminista (1929 - 2009): de Alfred Withehead a Bologna. Vol. II. Brasília: Liber Livro, 2011. 268p.

CARVALHO, José Mauricio de. Introdução à filosofia da razão vital de Ortega y Gasset. Londrina: CEFIL, 2002. 499p.

O século XX em El Espectador de Ortega y Gasset, a crise como desvio moral. Argumentos. Fortaleza: UFCE, Ano 2, N. 4, p. 9-18, ago./dez. 2010. Disponível em: $<$ http://www. periodicos.ufc.br/index.php/argumentos/article/view/224/224> Acesso em: 17 ago. 2015.

Ética. $1^{\text {a }}$. ed. São João Del-Rei: UFSJ, 2010. v. 1, 240 p.

CARVALHO, José Mauricio de; BESSA, Vanessa da Costa. Totalitarismo e ética em Ortega y Gasset. In: CARVALHO, José Mauricio de (Org.). Poder e moralidade, o totalitarismo e outras experiências antiliberais na modernidade. São Paulo: Annablume, 2012a,p. 105-130. 
DE CARVALHO, José Maurício; TOMAZ, Mauro Sérgio de Carvalho. Ortega y Gasset: universidade...

. Ortega y Gasset: crise da Espanha e problemas políticos. In: CASTRO LEAL, Ernesto (Org.). Monarquia e República. Lisboa: Universidade de Lisboa, 2012b, p. 117-139.

. Ética e Direito no discurso político de Ortega y Gasset. Kalagatos, Revista de Filosofia. Fortaleza: UECE, v. 9, n. 17, p. 97-127, Inverno 2012c. Disponível em: < $\underline{\text { http://www.uece.br/ }}$ kalagatos/dmdocuments/V9N17 Inv_2012_Artigo_Jose_Mauricio_Vanessa_Bessa.pdf $>$ Acesso em: 17 ago. 2015.

HUSSERL, Edmund. A crise da humanidade europeia e a Filosofia. Introdução e comentários de Urbano Zilles. Porto Alegre: EDIPUCRS, 1996. p. 13 - 55

ORTEGA Y GASSET, José. España Invertebrada. Obras Completas. v. III, 2. reimpresión, Madrid: Alianza, 1994a. 1994b.

. La rebelión de las masas. Obras Completas. v. IV, 2. reimpresión, Madrid: Alianza,

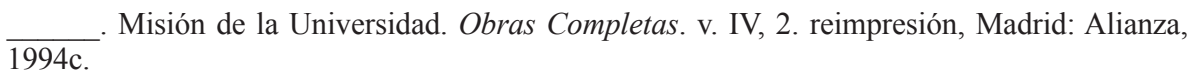
1994d.

Vicisitudes en las ciencias. Obras Completas. v. IV, 2. reimpresión, Madrid: Alianza, 1994e.

Las ciencias en rebeldia. Obras Completas. v. IV, 2. reimpresión, Madrid: Alianza, za, 1994f.

Sobre el estudiar y el estudiante. Obras Completas. v. IV, 2. reimpresión, Madrid: Alian1994 .

. El imperialismo de la Física. Obras Completas. v. IV, 2. reimpresión, Madrid: Alianza, $\overline{\mathrm{za}, 1994 \mathrm{~h} .}$

. La ciencia es mero simbolismo. Obras Completas. v. IV, 2. reimpresión, Madrid: Alian. En torno a Galileo. Obras Completas. v. V, 2. reimpresión, Madrid: Alianza, 1994i.

Conversión de la Física en Geometria. Obras Completas. v. V, 2. reimpresión, Madrid: Alianza, $1994 \mathrm{j}$.

. La idea de principio en Leibniz y la Evolucion de la teoria deductiva. Obras Completas. v. VIII, 2. reimpresión, Madrid: Alianza, 1994k.

. Bronca en la Física. In: Obras Completas. v.V. 2. Reimpresión, Madrid: Alianza, 19941. 1997.

. Investigações de Psicologia. Obras Completas. v. XII, 2. reimpresión, Madrid: Alianza,

PADORNO, Margarita Marqués. La misión de la universidad al servicio de la necessidad pública. Revista de Estudios Orteguianos, Madrid: Fundación Ortega y Gasset. v. II, n. 2, p.193-196, mai. 2001. 
ROMERO, Rafael García. Mission de la Universidad en el homenaje de 18 de noviembro de 1955. Revista de Estudios Orteguianos. Madrid: Fundación Ortega y Gasset. v. II, n. 2, p. 119-130, mai. 2001.

ROTHEN, José Carlos. A universidade e sua missão segundo Ortega y Gasset. In: ARAÚJO, José Carlos de Souza (Org.). In.: A universidade iluminista (1929 - 2009): de Alfred Withehead a Bologna. Vol. II. Brasília: Liber Livro, 2011, 268p p. 65 - 75

TOMAZ, Mauro Sérgio de Carvalho; CARVALHO, José Maurício de. Misión de la Universidad. Nova Águia. Portugal: Zéfiro, 2014. p 256 - 258. (Resenha) . Resenha de Sistema de la Psicologia de Ortega y Gasset. São João Del-Rei:

UFSJ, 2014. p. 145 - 148.

Submissão em: 14/08/2014

Aceite em: 04/08/2015

José Maurício de Carvalho é Especialista e Mestre em Filosofia pela UFJF, Doutor em Filosofia pela UGF-Rio. Professor Titular do Departamento de Filosofia da Universidade Federal de São João Del-Rei - UFSJ. Realizou estágios de pós-doutorado na Universidade Nova de Lisboa (1994 - UNL), Portugal e, posteriormente, no Programa de Pós-Graduação em Filosofia da Universidade Federal do Rio de Janeiro - UFRJ.

Endereço para correspondência: Rua Resende Costa, 154 - Largo da Cruz - Centro Histórico CEP: 36.300-118 - São João Del-Rei - MG E-mail: mauricio@ufsj.edu.br

Mauro Sérgio de Carvalho Tomaz é graduando em Licenciatura e Bacharelado em Filosofia na Universidade Federal de São João Del Rei/MG e bolsista de Iniciação 